Available online at: http://journal.unj.ac.id

Jurnal

Pensil

Pendidikan Teknik Sipil

Journal homepage: http://journal.unj.ac.id/unj/index.php/ipensil/index

\title{
IDENTIFIKASI BAHAYA DAN PENILAIAN RESIKO PADA PROSES PEKERJAAN PEMASANGAN ATAP SANDWICH PANEL
}

\section{HAZARDS IDENTIFICATION AND RISK ASSESSMENT IN THE SANDWICH PANEL ROOF INSTALATION WORK PROCESS}

\author{
Fira Nabila ${ }^{1}$ Pribantono ${ }^{2}$, Anisab ${ }^{3}$ \\ ${ }^{1,2,3}$ Universitas Negeri Jakarta, Jl. Rawamangun Muka Raya No. 11, DKI Jakarta, 13220 \\ 1iranabila2604@gmail.com, 2prihantono16@gmail.com, 3anisah mt@unj.ac.id
}

\begin{abstract}
Abstrak
P-ISSN: $2301-8437$

E-ISSN: $\underline{2623-1085}$

ARTICLE HISTORY

Accepted:

25 Agustus 2021

Revision:

2 September 2021

Published:

30 September 2021

ARTICLE DOI:

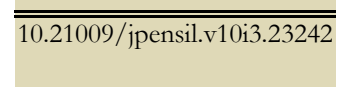

Penelitian ini bertujuan untuk mengetahui bahaya dan risiko pada proses pekerjaan pemasangan sandwich panel, proses identifikasi bahaya dan risiko menggunakan instrumen lembar Job Safety Analysis sedangkan penilaian risiko menggunakan metode semi kuantitatif W.T Fine J yang mengacu pada standar AS/NZS 4360:2004 tentang Risk Management. Pengambilan data dilakukan dengan menggunakan metode observasi lapangan, wawancara dan focus group discussion. Data yang diperoleh dianalisis dalam bentuk tabel identifikasi bahaya dan penilaian risiko kemudian dideskripsi secara objektif. Hasil penelitian menunjukkan bahwa terdapat enam bahaya dalam proses pekerjaan pemasangan sandwich panel antara lain bahaya mekanis, listrik, fisik, biologi, ergonomis dan biologis. Risiko yang teridentifikasi sebanyak 21 risiko dengan 7 level risiko Very High (33\%), 5 level Priority 1 (24\%), 6 level Substansial (29\%) dan 3 level Priority 3 (14\%).

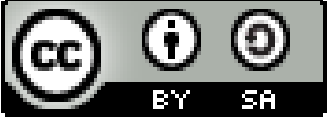

Jurnal Pensil : Pendidikan Teknik Sipil is licensed under a Creative Commons Attribution-ShareAlike 4.0 International License (CC BY-SA 4.0).

Kata kunci: Identifikasi bahaya, penilaian resiko, JSA, sandwich panel

\section{Abstract}

This study aims to determine the hazards and risks in the work process of installing sandwich panels, the process of identifying hazards and risks using the Job Safety Analysis sheet instrument while the risk assessment uses the semi-quantitative W.T Fine J method which refers to the AS/NZS 4360:2004 standard on Risk Management. Data collection was carried out using field observations, interviews and focus group discussions. The data obtained were analyzed in the form of a table of hazard identification and risk assessment and then described objectively. The results showed that there were six hazards in the work process of installing sandwich panels, including mechanical, electrical, physical, biological, ergonomic and biological hazards. The identified risks were 21 risks with 7 levels of Very High risk. (33\%), 5 levels of Priority 1 (24\%), 6 levels of Substantial (29\%) and 3 levels of Priority $3(14 \%)$.
\end{abstract}

Keywords: Hazard identification, risk assessment, JSA, sandwich panel 


\section{Pendahuluan}

$\begin{array}{cccc}\text { Pada } & \text { tahun } & 2017 & \text { Badan } \\ \text { Penyelengoara } & \text { Jaminan } & \text { Sosial } & \text { (BPJS) }\end{array}$ Ketenagakerjaan mencatat terjadi 123.041 kasus kecelakaan kerja dan meningkat di tahun selanjutnya menjadi 173.105 kasus. Pada tahun 2019 mengalami penurunan sebesar $26,40 \%$ menjadi 130.923 kasus dan terjadi peningkatan kembali menjadi 177.000 kasus di tahun 2020 (BPJS ketenagakerjaan, 2020). Sektor konstruksi adalah pekerjaan yang melibatkan banyak aktivitas dengan unsur risiko kecelakaan kerja yang tinggi, contohnya adalah pekerjaan di ketinggian (Wirdanikusumah, 2005).

Kegiatan konstruksi pembangunan stasiun LRT dilakukan di ketinggian tanpa melakukan penghentian kegiatan lalu lintas dibawah proyek. Pembangunan proyek stasiun dan depo LRT merupakan sebuah sistem Transit Oriented Development (TOD) dengan kereta api ringan untuk menghubungkan Jakarta dengan kota-kota di sekitarnya seperti Bekasi, Depok dan Bogor (JABODEBEK).

Proyek pembangunan stasiun LRT dibangun dengan tujuan memudahkan orang untuk berpergian dari satu titik ke titik lainnya karena terintegritas namun dalam pengerjaannya terdapat beberapa hambatan salah satunya yaitu terjadi peningkatan angka kecelakaan kerja di stasiun dukuh atas.

Berdasarkan data kecelakaan yang terjadi dari September 2020 sampai dengan Januari 2021 menunjukkan terjadi peningkatan angka kecelakaan kerja. Pada bulan September terjadi 24 kecelakaan dan meningkat menjadi 36 kasus di bulan Januari. Menurut hasil wawancara bersama HSE officer yang menyatakan bahwa kecelakaan terbanyak berasal dari pekerja pemasangan sandwich panel.

Pekerjaan pemasangan sandwich panel merupakan pekerjaan yang memiliki potensi bahaya dan risiko tinggi karena pekerjaan ini dilakukan di ketinggian, membutuhkan keterampilan dan melibatkan berbagai macam peralatan, alat-alat listrik dan banyaknya interaksi antar pekerja dengan peralatan. Dimulai dari proses unloading material yang dilaksanakan pada malam hari (windows time) pukul 22.0004.00 WIB, menyebabkan pekerja mengalami kelelahan dan hilang fokus. Material sandwich panel itu sendiri memiliki ukuran yang besar yaitu dengan berat 150 $\mathrm{kg}$ dan memiliki ujung sisi yang tajam sehingga saat proses penggeseran dan pengangkatan sandwich panel dapat menimbulkan gerakan tidak ergonomis yang merugikan pekerja dikarenakan ruang gerak kerja yang terbatas dan risiko cedera seperti luka sayat, luka gores, terbentur dan terjepit pada pekerja.

Oleh karena itu, mengingat potensi bahaya dan risiko dari pekerjaan ini tergolong tinggi maka diperlukan upaya pencegahan yaitu melakukan manajemen risiko dengan memperhatikan aspek keselamatan agar tercipta kondisi yang aman dan sehat dengan tujuan meningkatkan produktivitas dan kesejahteraan pekerja itu sendiri. (Cristiyanto, 2007). Salah satu upaya pencegahan risiko tinggi adalah dengan mengidentifikasi bahaya dan penilaian risiko karena risiko tidak dapat ditentukan tanpa mengenal bahaya sehingga upaya pencegahan dan pengendalian risiko tidak bisa dijalankan (Soehatman Ramli, 2010:54).

Tujuan penelitian diadakan untuk mengetahui proses identifikasi bahaya dan menilai risiko pada proses pekerjaan sandwich panel sebagai upaya pencegahan dalam menghadapi kecelakaan yang sudah terjadi sebelumnya dan menemukan rekomendasi pengendalian yang tepat agar tercapainya program zero accident dalam proyek

\section{Metode Penelitian}

Berdasarkan dari cara pengambilan data, penelitian ini masuk ke dalam penelitian observasional karena peneliti hanya berperan dalam melakukan pengamatan tanpa memberikan perlakuan khusus dan intervensi. Berdasarkan analisisnya, penelitian ini termasuk ke dalam jenis penelitian deskriptif karena membuat 
gambaran tentang suatu keadaan secara objektif dan menyeluruh. Jika diliha dari segi tempat, maka penelitan ini termasuk ke dalam penelitian lapangan karena data primer didapatkan melalui observasi dan wawancara. Lokasi penelitian ini dilaksanakan di proyek pembangunan Stasiun LRT Dukuh Atas, yang terletak di Jalan Setia Budi Tengah No.29, RT.2/RW.3, Kuningan, Setia Budi, Kota Jakarta Selatan. Waktu penelitian dilakukan dalam kurun waktu 1 bulan yaitu pada 11 Februari 2021- 11 April 2021. Objek dalam penelitian ini adalah bahaya dan risiko yang terdapat dalam proses pekerjaan pemasangan sandwich panel dari material sampai ke proyek hingga terpasang. Dalam penelitian ini, proses mengidentifikasi bahaya dilakukan menggunakan form Job Safety Analysis (JSA) berdasarkan OSHA 3071 revisi 2002, form tersebut berisi tentang urutan kerja, bahaya, risiko dan pengendalian yang ada dalam proses pekerjaan sandwich panel. Data-data yang didapatkan dalam tahap identifikasi bahaya yaitu dengan melakukan observasi, wawancara. Data yang diperoleh dari wawancara sebagai bentuk cross check untuk mengukur objektivitas pengamatan di lapangan.

\section{Hasil Penelitian dan Pembahasan \\ Identifikasi Bahaya}

Pada proses pekerjaan unloading material terdapat 7 tahapan kerja, memiliki 5 bahaya keselamatan dan kesehatan kerja yaitu bahaya mekanis, fisik, biologi, ergonomi dan psikologi.dan pemasangan gutter

Pada proses pekerjaan pemasangan gutter material terdapat 8 tahapan kerja, memiliki 5 bahaya keselamatan dan kesehatan kerja yaitu bahaya mekanis, fisik, biologi, ergonomi dan psikologi.dan pemasangan gutter

Pada proses pekerjaan pemasangan sandwich panel puncak dan sandwich panel dibawah gutter, proses pemasangan gutter memiliki 6 bahaya keselamatan dan kesehatan kerja yaitu bahaya mekanis, biologi, fisik, biologis, ergonomi dan listrik.

Pada proses pekerjaan finishing memiliki 5 bahaya keselamatan dan kesehatan kerja yaitu bahaya mekanis, biologis, fisik dan ergonomis dengan 9 risiko kecelakaan kerja.

\section{Penilaian Risiko}

1. Jatuh dari ketinggian

Risiko jatuh dari ketinggian masuk ke dalam semua jenis pekerjaan pada proses pemasangan sandwich panel. Risiko ini memiliki nilai risiko sebesar 750 dengan tingkat risiko very high. artinya pekerjaan ini memiliki risiko yang serius karena berkaitan dengan pekerjaan di ketinggian yang menyebabkan cacat bahkan kematian.

2. Mata terkena gram/serpihan besi

Risiko mata terkena gram/serpihan besi berkaitan dengan aktivitas pemotongan material menggunakan gerinda dan pengeboran. Risiko ini memiliki nilai 750 dengan tingkat risiko karena apabila terkena gram/serpihan besi dari proses membor dan proses gerinda maka dapat menyebabkan kebutaan apabila terkena bola mata.

3. Tertimpa material dari atas

Risiko dapat terjadi karena proses pengikatan material dilakukan di area ground floor yang berisiko kejatuhan material dari atas. Risiko ini memiliki nilai risiko sebesar 450 dengan tingkat risiko very high. Risiko ini dapat menimbulkan risiko serius yaitu kerusakan tubuh, cacat sementara atau permanen bahkan bisa menghilangkan nyawa.

\section{Terpapar covid}

Risiko terpapar covid mencakup ke dalam semua jenis pekerjaan pada proses pemasangan sandwich panel, Risiko ini memiliki nilai risiko sebesar 450 dengan tingkat risiko very high. artinya risiko terpapar covid ini dapat menimbulkan risiko serius karena apabila terpapar, maka bisa menyebar ke sesama pekerja sehingga bisa menimbulkan gangguan pernapasan, sesak nafas bahkan bisa menimbulkan kematian apabila tidak segera dicegah/diputus rantai penyebarannya. 
5. Gagal pengangkatan

Risiko gagal pengangkatan hanya berkaitan dengan aktivitas lifting material. Risiko ini memiliki nilai risiko sebesar 450 dengan tingkat risiko substansial. risiko ini menimbulkan konsekuensi yang serius karena apabila gagal pengangkatan maka bisa menyebabkan kerusakan lokal lingkungan karena material jatuh saat diangkat oleh tower crane serta material dan lifting gear yang jatuh bisa menimpa pekerja di bawahnya dan menyebabkan cedera bahkan kematian.

6. Sling putus

Risiko sling putus pada saat pekerjaan lifting material yang ada di jenis pekerjaan unloading, pemasangan gutter, sandwich panel dibawah gutter dan puncak. Risiko ini memiliki nilai risiko sebesar 450 dengan tingkat risiko substansial. artinya apabila sling putus saat proses lifting maka dapat menyebabkan material jatuh sehingga material rusak dan menyebabkan luka bahkan kematian apabila tertimpa pekerja dibawahnya.

\section{Tersengat listrik}

Risiko tersengat listrik berkaitan dengan pekerjaan handtools yaitu saat proses pemotongan menggunakan gerinda daya 540 watt dan proses pengeboran daya 550 watt. Risiko ini memiliki nilai risiko sebesar 450 dengan tingkat risiko substansial artinya sengatan listrik dapat menyebabkan risiko yang serius yaitu pekerja lemas, pingsan hingga kematian.

8. Luka gores dan luka sayat

Material sandwich panel memiliki ujung sisi yang tajam dan volume yang besar. Risiko ini memiliki nilai risiko sebesar 300 dengan tingkat risiko substansial artinya risiko ini dapat menimbulkan risiko serius yaitu kerusakan tubuh, cacat sementara atau permanen bahkan bisa menghilangkan nyawa.

9. Kepala terbentur

Risiko kepala terbentur berkaitan dengan aktivitas lifting material. Risiko ini memiliki nilai risiko sebesar 300 dengan tingkat risiko substansial. artinya risiko ini dinilai penting khususnya pada saat pekerja menerima sandwich panel pada saat lifting material yang menyebabkan pendarahan di kepala dan hilang kesadaran akibat ujung material yang tajam dan volume material yang besar.

10. Pingsan

Risiko pingsan masuk ke dalam semua jenis pekerjaan pada proses pemasangan sandwich panel, dimulai dari pekerjaan unloading material, pekerjaan pemasangan gutter, pekerjaan pemasangan sandwich panel puncak, pekerjaan pemasangan sandwich panel dibawah puncak dan pekerjaan finishing. Risiko ini memiliki nilai risiko sebesar 250 dengan tingkat risiko substansial. artinya risiko ini dapat menimbulkan risiko serius yaitu pekerja yang mengalami pingsan menyebabkan penderita terjatuh, terbentur dan mengalami cedera.

11. Tertabrak truk

Risiko truk terperosok hanya terdapat pada pekerjaan unloading material yaitu pada saat truk memasuki area on site. Risiko ini memiliki nilai risiko sebesar 300 dengan tingkat risiko substansial artinya risiko ini dapat menimbulkan risiko serius yaitu kematian akibat benturan yang ditimbulkan dari truk material tersebut.

12. Truk terperosok

Risiko truk terperosok hanya terdapat pada pekerjaan unloading material yaitu pada saat truk memasuki area on site. Risiko ini memiliki nilai risiko sebesar 250 dengan tingkat risiko substansial. artinya risiko ini dapat menimbulkan risiko serius yaitu apabila truk terperosok maka material bisa tergelincir, jatuh dan rusak serta bisa menimbulkan luka bahkan kematian pada supir truk dan pekerja sekitar.

\section{Terpeleset}

Risiko terpeleset masuk ke dalam semua jenis pekerjaan pada proses pemasangan sandwich panel, dimulai dari pekerjaan unloading material, pekerjaan pemasangan gutter, pekerjaan pemasangan sandwich panel puncak, pekerjaan pemasangan sandwich panel dibawah puncak dan pekerjaan finishing. Risiko ini dapat terjadi saat pekerja melakukan proses 
pemasangan dan naik turun menggunakan akses kerja scaffolding. Dampak negatif yang mungkin timbul akibat dari risiko ini adalah pekerja dapat mengalami cidera seperti patah tulang, luka bahkan cacat. Risiko ini memiliki nilai risiko sebesar 150 dengan tingkat risiko substansial. artinya risiko ini dapat menimbulkan risiko penting yaitu kerusakan tubuh, cacat sementara atau permanen bahkan bisa menghilangkan nyawa.

14. Material jatuh

Risiko material jatuh dan rusak sangat berkaitan dengan aktivitas lifting material yang mana terdapat pada pekerjaan unloading material, pemasangan gutter, pemasangan panel puncak dan pemasangan panel dibawah gutter. Risiko ini memiliki nilai risiko sebesar 150 dengan tingkat risiko substansial. artinya risiko ini dapat menimbulkan risiko penting, yaitu apabila material jatuh maka dapat menimbulkan kerusakan di area lifting, menimpa pekerja dibawahnya dan bisa menimbulkan kerugian akibat kerusakan material tersebut.

\section{Tertimpa lifting gear}

Risiko tertimpa lifting gear hanya ada saat melakukan pemeriksaan lifting gear sebelum pekerjaan dilakukan. Risiko ini memiliki nilai risiko sebesar 150 dengan tingkat risiko priority 3 artinya risiko ini dapat menimbulkan luka memar dan cedera pada jari kaki atau kaki meskipun perusahaan sudah melakukan upaya pengendalian yaitu memakai sepatu safety/boot.

\section{Gangguan pendengaran}

Risiko gangguan pendengaran masuk ke semua pekerjaan pemasangan sandwich panel Risiko gangguan pendengaran memiliki nilai risiko 150 dengan tingkat risiko substansial. karena pekerjaan ini dilakukan bersamaan dengan pekerjaan lain secara bersamaan yang mana memaparkan suara bising dari peralatan yang menyebabkan gangguan pendengaran seperti tuli sementara, stress, daya ingat menurun dan sulit fokus.
17. Material tergelincir dari truk

Risiko material tergelincir dari truk hanya ada pada pekerjaan unloading material khususnya pada saat aktivitas truk memasuki area on site. Risiko ini memiliki nilai risiko sebesar 90 dengan tingkat risiko substansial. artinya risiko ini dapat menimbulkan risiko serius yaitu apabila material tergelincir maka material akan rusak dan kerugian waktu bagi perusahaan karena material yang rusak tidak bisa dipasang sehingga harus dikembalikan ke produsen.

18. Low back pain

Risiko low back pain sangat berkaitan dengan aktivitas seperti pengikatan material dan housekeeping. Low back pain mencakup ke semua pekerjaan yang ada di proses pemasangan sandwich panel. Risiko ini memiliki nilai 150 dengan level risiko priority 3.

19. Terjepit pin shackle

Risiko terjepit pin shackle berkaitan dengan aktivitas rigging dan lifting material dalam semua proses pekerjaan pemasangan sandwich panel. Risiko ini memiliki nilai risiko sebesar 60 dengan tingkat risiko substansial artinya risiko ini dapat mengakibatkan cidera dan memar pada jari tangan pekerja. titik jepit pada lifting gear.

20. Tersandung

Risiko tersandung berkaitan dengan semua proses pekerjaan pemasangan sandwich panel khususnya aktivitas seperti persiapan area dan peralatan, housekeeping dan pelepasan stiker. Risiko ini memiliki nilai 60 dengan level risiko priority 3 karena jika pekerja tersandung maka akan menyebabkan memar pada anggota tubuh yang terbentur

21. Iritasi tangan

Risiko ini memiliki nilai risiko sebesar 50 dengan tingkat risiko substansial karena bahan yang digunakan yaitu bahan kimia sealant yang apabila kontak langsung dengan kulit terus menerus akan mengakibatkan infeksi kulit 


\section{Simpulan}

Berdasarkan hasil penelitian yang telah penulis lakukan pada perusahaan Adhi Karya khususnya pada proses pekerjaan pemasangan sandwich panel di proyek pembangunan LRT Dukuh Atas, dapat diambil kesimpulan sebagai berikut:

(1) Proses pekerjaan pemasangan sandwich panel terdiri dari 5 tahapan pekerjaan yaitu pekerjaan unloading material, pekerjaan pemasangan gutter, pekerjaan pemasangan sandwich panel puncak, pekerjaan pemasangan sandwich panel dibawah gutter dan pekerjaan finishing; (2) Hasil identifikasi bahaya dan risiko yang telah dilakukan menunjukkan bahwa terdapat 21 risiko dengan level risiko Very High (33\%), Priority 1 (24\%), Substansial $(29 \%)$ dan Priority 3 (14\%) yang berasal dari proses pekerjaan pemasangan sandwich panel meliputi tertimpa material dari atas, terpeleset, terpapar covid, material tergelincir dari truk, truk terperosok, material jatuh, tertabrak truk, terjepit pin shackle, tertimpa lifting gear, tersandung, low back pain, gangguan pendengaran, pingsan, gagal pengangkatan, jatuh dari ketinggian luka gores dan luka sayat, kepala terbentur, sling putus, tersengat listrik, mata terkena gram/serpihan besi, iritasi tangan; (3) Jumlah bahaya dan risiko pemasangan sandwich panel apabila menggunakan tower crane lebih banyak jika dibandingkan dengan risiko pemasangan sandwich panel dengan menggunakan mini crane yang berjumlah 13 risiko. Rekomendasi pengendalian yang digunakan berdasarkan hierarki pengendalian yaitu pengendalian administratif, teknis dan APD (Alat Pelindung Diri); (4) Pada proses pekerjaan unloading material dan pemasangan gutter terdapat 7 tahapan kerja, proses unloading material dan pemasangan gutter memiliki 5 bahaya keselamatan dan kesehatan kerja yaitu bahaya mekanis, fisik, biologi, ergonomi dan psikologi dengan 19 risiko kecelakaan kerja. 2 risiko kecelakaan kerja yaitu risiko terjatuh dari ketinggian dan tertimpa material dari atas memiliki level risiko tertinggi very high (10\%); (5) Pada proses pekerjaan pemasangan sandwich panel puncak dan sandwich panel dibawah gutter, proses pemasangan gutter memiliki 6 bahaya keselamatan dan kesehatan kerja yaitu bahaya mekanis, biologi, fisik, biologis, ergonomi dan listrik dengan 19 risiko kecelakaan kerja. 2 risiko kecelakaan kerja tertinggi $(10 \%)$ yaitu risiko terjatuh dari ketinggian dan tertimpa material dari atas; (6) Pada proses pekerjaan finishing memiliki 5 bahaya keselamatan dan kesehatan kerja yaitu bahaya mekanis, biologis, fisik dan ergonomis dengan 9 risiko kecelakaan kerja. 1 risiko kecelakaan tertinggi (11\%) tingkat very high yaitu risiko jatuh dari ketinggian.

\section{Daftar Pustaka}

Badan Penyelenggara Jaminan Sosial Kesehatan Ketenagakerjaan. (2017). Hingga 2017, BPJS Ketenagakerjaan Tangani 123.041 Kasus Kecelakaan Kerja. Jakarta: BPJS Ketenagakerjaan.

Departemen Tenaga Kerja RI, 1970. Undang-undang No. 1 Tahun 1970 tentang Keselamatan Kerja. Jakarta : Depnaker RI.

Departemen Tenaga Kerja RI, 1996. Peraturan Menteri Tenaga Kerja RI No. Per05/MEN/1996 tentang Sistem Managemen Keselamatan dan Kesehatan Kerja. Jakarta : Depnaker RI.

Ervianto, W. I. (2005). Manajemen Proyek Konstruksi (Edisi Revisi). Yogyakata: Andi.

Firdaus, Tesis Magister, "Perilaku Balok Beton Sandwich Dalam Menerima Beban Lentur, ITB, 2000

ILO. Data Kecelakaan Kerja Tahun 2015. Jakarta: Departemen Kesehatan; 2013.

OHSAS 18001 : 2007 Occuptional Health and Safety Management System, (2007). 
Peraturan Menteri Tenaga Kerja dan Transmigrasi No. PER. 01/MEN/1980 Tentang Keselamatan dan Kesehatan Kerja pada Konstruksi Bangunan. Sekretariat Kabinet RI. Jakarta.

Peraturan Menteri Tenaga Kerja dan Transmigrasi Nomor 01 Tahun 1980 tentang Keselamatan dan Kesehatan Kerja pada Konstruksi Bangunan

Peraturan Menteri Tenaga Kerja dan Transmigrasi Nomor 05 Tahun 1985 tentang Pesawat Angkat dan Angkut.

Peraturan Menteri Tenaga Kerja dan Transmigrasi Nomor 09 Tahun 2010 tentang Operator dan Petugas Pesawat Angkat dan Angkut.

Shofiana, I. (2015). Identifikasi Potensi Babaya Pekerjaan Di Ketinggian Pada Proyek Pembangunan Gedung Parkir Rumah Sakit Telogorejo (Studi Deskriptif Pada Proyek Konstruksi Oleh Pt. Adhi Karya Semarang) (Doctoral dissertation, Universitas Negeri Semarang).
Ramli, Soehatman, 2010, Sistem Manajemen Keselamatan dan Kesehatan Kerja OHSAS 18001, Jakarta: PT. Dian Rakyat.

Sukri Sahab, 1997, Teknik Manajemen Keselamatan dan Kesehatan Kerja, Jakarta: PT. Bina Sumber Daya Manusia.

Syamsi, Ibnu. 1994. Pokok-Pokok Organisasi dan Manajemen. Jakarta: Rineka.

Tarwaka, 2014, Keselamatan dan Kesehatan Kerja Manajemen dan Implementasi K3 di Tempat Kerja, Surakarta: Harapan Press.

Wibawa, Zeinfahmi Dwireski. 2016. Risk Assessment Kecelakaan KerjaPekerjaan Atap di Pembangunan Gedung Oleh PT.PP. Skripsi. Surabaya: Universitas Airlangga

Wulandari, Septia. 2011. Identifikasi Bahaya, Penilaian dan Pengendalian Risiko Area Produksi Line 3 Sebagai Upaya Pencegahan Kecelakaan Kerja di PT.Coca Cola Amatil Indonesia Central Java. Surakarta: Universitas Sebelas Maret. 